\title{
The Value of NATO Option for a New Member
}

\author{
Vesa Kanniainen \\ University of Helsinki, HECER and CESifo \\ and \\ Staffan Ringbom \\ Hanken School of Economics and HECER
}

Discussion Paper No. 393

June 2015

ISSN 1795-0562

HECER - Helsinki Center of Economic Research, P.O. Box 17 (Arkadiankatu 7), FI-00014 University of Helsinki, FINLAND, Tel +358-2941-28780, E-mail info-hecer@helsinki.fi, Internet www.hecer.fi 


\title{
The Value of NATO Option for a New Member *
}

\begin{abstract}
The paper introduces a welfarist approach to the national safety of a nation with membership in a defense alliance as an option. The members are risk averse but heterogeneous in their safety classification. There are two public goods as insurance devices, the domestic military budget and the incremental safety provided by the membership in the alliance. The commitment of the alliance in the creation of safety is, however, imperfect. A sufficient condition is stated for the non-membership. Under a positive option value of the membership, several adverse incentive effects shaping the option value are identified, including the incentive to free ride in domestic defense investment and a moral hazard effect in terms of national commitment to the defense effort. The cost of participation is determined in the spirit of the median voter theorem. The alliance equilibrium is shown to be of two potential types, a stable alliance equilibrium with a positive mass and or a degenerate one with one member only. The driving force in the adjustment of the alliance is its size relative to the safety class of the median voter. Expectations of the decision making of the co-members concerning the commitment can result in multiple equilibria.
\end{abstract}

JEL Classification: H2O, H57, I21, D63

Keywords: alliance, national security, free riding, safety classification

Vesa Kanniainen

Department of Political and Economic Studies University of Helsinki

P.O. Box 17 (Arkadiankatu 7)

FI-00014 University of Helsinki

FINLAND

e-mail: vesa.kanniainen@helsinki.fi
Staffan Ringbom

Department of Economics

Hanken School of Economics

P.O. Box 479 (Arkadiankatu 7)

$\mathrm{FI}-00101$ Helsinki

FINLAND

e-mail: staffan.ringbom@hanken.fi

* The earlier draft of the paper was presented at the CESifo Public Economics Workshop, Munich, April 16-18, 2015. The authors are grateful to the participants for helpful comments. 


\section{Introduction}

The fundamental incentive to establish a defense coalition derives from the asymmetry of military capacities. A coalition produces safety as an instrument for deterrence against an outside threat. ${ }^{1}$ The North Atlantic Treaty Organization, NATO, was created after the Second World War in 1949 as a joint defense alliance. The active ongoing debate both in Finland and Sweden about the potential membership in NATO demands a cost-benefit analysis. ${ }^{2}$ In the political rhetoric, both countries assume that such an option is available. Sweden has taken a further step in her security policy eliminating the draft and starting to build a professional military. Finland has chosen a different approach building on the draft.

Early contributions to the theory of coalition formation include Gamson [1961] who characterized the basic ingredients in the coalition formation. The economic analysis of alliances has its roots in Olson and Zeckhauser [1966], van Ypersele de Strihou [1967] and Hirshleifer [1983]. Most contributions can be attributed to Sandler's work over 20 years (1975-1995) who - together with Hartley [2001] also provided the overview. In their seminal paper, Olson and Zeckhauser [1966] had established the inefficiency of the defense investment in the absence of commitment to the efficient level of safety. Subsequently, Weber and Wiesmeth [1991] introduced a mechanism allowing the implemen-

\footnotetext{
${ }^{1}$ The theory of deterrence was introduced by Schelling [1960] in his seminal book on conflicts (1960).

${ }^{2}$ Originally, NATO had 12 founding members including Belgium, Canada, Denmark, France, Iceland, Italy, Luxembourg, Netherlands, Norway, Portugal, United Kingdom and United States. The enlargement has taken place in several stages. In 1952, Greece and Turkey became members and Germany in 1955 (including the former German Democratic Republic in 1990). Spain became a member in 1982 and the former Warsaw Pact countries in two waves (Czech Republic, Hungary, Poland, Bulgaria, Estonia and Latvia in 1999 and Lithuania, Romania, Slovakia, Slovenia, Albania and Croatia in 2009). Without the formal retirement of her membership, France broke up her participation with the NATO decision making and in defense during the period 1959-1993. The speculated candidate countries for a membership include Finland, Sweden, Georgia, Montenegro, Bosnia-Hertzegovina and Ukraine.
} 
tation of an efficient allocation, characterized by proportional burden sharing and cost monotonicity. In van Ypersele de Strihou [1967], some ally-specific benefits were private. Another idea of heterogeneity of the members is part of Hirshleifer's proposal on the best-shot and weakest-link technologies. The key observation concerning NATO in Sandler and Hartley [2001] was the idea of security exploitation hypothesis. Originally, the idea of exploitation of the great by the small was introduced by Olson [1965] and discussed by Olson and Zeckhauser [1966] in the context of international public goods. Subsequently, Boadway and Hayaschi [1999] established that population size and per capita income have different implications for the national voluntary contributions of international public goods.

Sandler and Hartley [2001] reported calculations on the defense burden and the average benefit share for the USA and NATO-Europe for 1970, 1980 and 1985. While the defense burden of the USA in the latter year was 72,82 and the average benefit share was 34,19, these figures were 25,17 and 40.28 for the NATO-Europe. It indeed appears that the NATO-Europe always has chosen free riding within the alliance! ${ }^{3}$ The traditional idea of defense as a homogeneous pure public good has been challenged by literature which disaggregated the public good "into self-insurance" and "self-protection", originally introduced by Ehrlich and Becker [1972] (see Lohse et al. [2012], Ihori et al. [2014]). Ray and Vohra [1999] established the existence of a stationary sub-game perfect equilibrium with a coalition with widespread externalities between the members. Their results were, however, based on the assumption of binding agreements within a military alliance. Subsequent applications to the coalition formation included the gradual formation of trading blocks [Macho-Stadler and Xue, 2007]. The member countries were assumed to agree on the tariffs on mutual trade imposing a negative externality from the bloc to the non-bloc members. They examined whether it is in the interest

\footnotetext{
${ }^{3}$ Financial Times reported in January 2014 that the US is currently more concerned than ever of the free riding of the European member states.
} 
of the coalition to accept new members.

In this paper, we analyse the potential membership from the cost-benefit perspective and we characterize the value of the membership option for a potential member. There is a trade-off between private goods and security as the public good. The security provision is different from the earlier work. Unlike the earlier papers on coalition formation, in our paper the countries are the subject of a country-specific safety (risk) classification. They derive national security from their domestically allocated defense investment and the resources allocated to the provision of the collective security provided by the coalition. In our model, we introduce a number of mechanisms which are relevant to the benefit/cost analysis of the membership (Sections 2 and 3 ). The basic parameter is the heterogenous safety classification of countries. The model builds on the classic Olson and Zeckhauser [1966] but adds more structure. First, the expected degree of commitment of the alliance is made explicitly probabilistic. A benefit/cost ratio is derived for the membership and the free riding incentive is analyzed. Second, a potentially devastating effect of the reduced risk from the membership on the national defending effort is introduced. The case for extreme free riding (moral hazard) with the abolishment of domestic investment in defense is considered. Third, the retaliation initiated by the potential enemy is introduced. For the coalition, the production of collective security is analyzed in terms of the public good provision by an alliance with heterogeneous members and the decisive role of the median voter (Section 4). ${ }^{4}$ The incentives of the low-risk members not to participate are examined and the equilibrium size of the coalition and the equilibrium membership fee are derived. Expectations of the decision making of the co-members concerning the commitment are shown to result potentially in multiple equilibria.

\footnotetext{
${ }^{4}$ The Samuelson condition for the efficiency of the public good production is violated for two reasons. First, there is a welfare loss in financing the production of safety. Second, each member country is free riding.
} 


\section{Military budget and national security}

\section{$2.1 \quad$ Model structure}

There are three stages in the model, $(0,1,2)$. In stage 0 , a mass of $n$ risk averse nations facing an outside threat builds up an alliance committing to provide a common public good, collective security, to be denoted by $G$ as an insurance device. ${ }^{5}$ In stage 1 , the nation-specific safety (risk) classes are revealed for all alliance members. As a consequence, the nations re-evaluate their membership in terms of costs and benefits attached to the alliance. The cost of the membership and the alliance size are determined. In stage 2, an adverse (and permanent) shock into the safety class of a potential new member materializes resulting in the evaluation of the option value of the alliance membership.

The alliance dynamics in stage 1 is analyzed in terms of the median voter theorem. A median voter proposes the membership fee in the forward-looking manner understanding that all members - including herself - will optimize the national tax and defense policy either as a member or as a non-member in the light of the proposal. Therefore, it is not possible to solve for the alliance equilibrium before knowing in which way the optimal national tax rates and defense budgets are adjusted given the proposed cost of membership. For this reason, the model is solved first in stage 2 which also provides the solution for the option value of a potential new member. Having this solution at hand, the alliance equilibrium is solved in Section 4.

\subsection{Membership in an alliance}

To analyze the option value of the membership for a potential new member in an alliance in stage 2 , the paper works out a welfarist approach. Such a

\footnotetext{
${ }^{5}$ The incentive of a potential enemy to attack is not modelled. In the background, there is an idea of a competition for some valuable resource. The alliance formation as an insurance device represents a means of deferral against such a threat.
} 
research task implicitly necessitates some heterogeneity between the nations. For some potential members, the option may have a positive value, for others it may not. The key source of heterogeneity is the safety class of a potential member. The heterogeneity arises from different locations in the world where a potential enemy operates in terms of a sphere of interest or may have a plan to extend her territory.

In Sections 2 and 3 of the paper, the welfare optimum is analyzed from the perspective of a potential marginal member thus taking as given the collective defense capacity of the alliance and its expected commitment to support its members. As these two sections focus on the incentives of a single member or non-member, the size of the alliance, $n$, and the membership contribution $F$ are exogenous. Subsequently, the focus of the analysis in Section 4 is moved to the decision making of the alliance with the heterogenous preferences of its members. There, the heterogeneity of the interests of the members results in a collective decision making assumed to satisfy the median voter theorem. The ex ante probability of commitment of the alliance to provide the security for its member which is a subject of a hostile attack is given by $0<\mu \leq 1$ and is interpreted as the measure of the credibility of the commitment.

The credibility of the commitment within the alliance is a serious issue. The alliance members not only consume the public good but in the first place also create it. Should a crisis arise, the credibility of the commitment becomes an issue and a subject of an incentive problem ex post. The common good will not be automatically available, as with a positive probability, a moral hazard incentive arises should a conflict materialize. ${ }^{6}$ The alliance members

\footnotetext{
${ }^{6}$ Article 5 of the NATO treaty, requiring member states to come to the aid of any member state subject to an armed attack, was invoked for the first and only time after 9/11 attacks in 2001 after which troops were deployed to Afghanistan under the NATO-led ISAF. The credibility of the NATO defense against a prospective Soviet invasion has not been tested. As a historical example of imperfect commitment, one can point to another case. There was a plan between the Finnish and Swedish military in the 1930s concerning the Swedish military and equipment to be transferred through Finland for the military operations should Sovietunion attack Finland. When the attack started in November 1939 leading to the Winter War, the Swedish policy makers withdrew from the joint military
} 
understand the moral hazard and may view their involvement as costly. 7

For these reasons and as the realization of the military threat is not modelled, the approach in this paper takes the commitment probabilistic recognizing the potential moral hazard. ${ }^{8}$ The participation conditions on the membership have to be satisfied. Incorporating the participation issue in the model, makes the size of the alliance, $n$, endogenous. A potential new member, however, takes the decisions of the alliance as given when solving for the option value of the membership from her national perspective.

To be now more specific, the safety class of the existing and a potential member, say $i$, is denoted by $s^{i}$ and it is assumed to be uniformly distributed over a support

$$
s^{i} \epsilon\left[s^{L}, s^{U}\right] .
$$

The degree of heterogeneity of the member countries is thus measured by the length of the support $s^{U}-s^{L}$. The risk class is the inverse of the safety class. ${ }^{9}$ The size of the alliance denoted by $n$ is a "mass",

plan.

${ }^{7}$ In fact, those costs may - in the real world - also be asymmetric. A potential reason why NATO would apparently prefer Finland and Sweden joining the alliance is the lucrative idea of linking the burden of the safety of the near-by Baltic states to the Finnish and Swedish defense capacity. Such a delegation of the burden may be asymmetric in the real world. Though not modelled explicitly in the current paper, the effect of the asymmetry on the option value of the membership is quite trivial. From this perspective, it may be difficult to explain why NATO accepted the Baltic states as members of NATO in the first place without calculating the cost of redeeming the commitment to these states. Such evaluations have obviously been undertaken subsequently in the case of Georgia and Ukraine which both have been expressed their preference for the membership in NATO.

${ }^{8} \mathrm{~A}$ necessary condition for the case of a strong commitment with $\mu=1$ is that the military capacity of the alliance exceeds that of the potential enemy. Then, the Tullock idea of the modeling of contests appears a helpful analytic tool, see Tullock [1967],Tullock [1980]. For analytic approaches to the Tullock idea, see Hirshleifer [1989], Konrad [2009] and Chowdhury and Sheremeta [2011], for example.

${ }^{9}$ History of each country provides a clue as to its safety class. Countries with a high safety classification apparently include Canada, United Kingdom, Spain and Portugal to name a few. Countries with a lower safety classification apparently include the former Warshaw Pact countries which joined NATO when the membership became feasible after 


$$
n=1+\Delta, \quad \Delta \geq 0
$$

The national military budget $(B)$ determines the resources available for the national defense $(D)$. For a non-member, the national security $(S)$ represents a public good - in a sense feeling of safety - and is modelled as a production function

$$
S^{i}=s^{i}+\beta D, \quad \beta \leq 1
$$

In (1), we have introduced an important distinction between the ability to defend, $D$, and a measure of commitment to provide nationally a defense effort, $\beta \leq 1$. For a non-member, we normalize $\beta$ to be one. When a country becomes a member in an alliance, it may have an incentive to free ride by cutting back its national defense investment, $D$. Moreover, an additional moral hazard may arise in terms of the national defense effort resulting in $\beta<1$. Therefore, the defense capacity represents an imperfect signal of the national commitment of providing the defense effort nationally. ${ }^{10}$

As a member, each country allocates her national military budget between the national defense capacity and the collective good within the alliance,

$$
B=D+F
$$

where $F$ is the contributions of the members, assumed to be equal across the members.. The resulting collective defense capacity created and its role in the

the Soviet collapse not to mention the Baltic States. Of the non-member countries, Finland probably has a low safety classification as has Sweden in the current state of affairs in the Baltic Sea area.

${ }^{10}$ Olson and Zeckhauser (1966) identified the moral hazard incentive of an alliance member associating it with the national military budget. We think that our suggestion of the imperfect national commitment to an efficient use of the military capacity is an extension to this view. For example, NATO expects its members allocate 2 per cent of their GDP into the defense. With the exceptions of the USA and Estonia, no other member adheres to this commitment pointing to free riding. 
crisis response operations represents a public good. The collective security produced by the alliance, say $G$, is related to the size of the alliance, $n$, the contributions of the members, $F$, and the expected commitment, $\mu$. However, the value of the collective public good for the members varies is related to her safety class, $s^{i}$. For a country with a high safety classification, the value is lower than for a country with a low safety classification. Therefore, and to capture all these mechanisms, we work with a somewhat complicated formulation

$$
G^{i}=\mu n F^{\alpha} e^{-s^{i}} .
$$

Though this approach involves a number of mechanisms and looks involved, it turns out to be a fruitful one. It highlights the idea that the valuation of the collective public good is heterogenous. The variable $n$ captures the security externality within the alliance.

An additional mechanism is captured by the exponential $\alpha$. It will subsequently turn out that a condition

$$
\alpha<1
$$

is sufficient to determine the equilibrium value of the contribution $F$ of the members. This points to the case of diminishing returns and it arises for rather conventional reasons.

Then, the security production function in a member country $i$, taken to be additively linear, is expressed as

$$
S^{i}=s^{i}+\beta D+G^{i} .
$$

The participation constraint for a member in the coalition can then be stated as $\beta D_{M}+G \geq D_{N}$ with $M$ denoting the membership and $N$ the nonmembership. The moral hazard arises from that the decision of operating $D$ remains under national discretion. Then, as the domestic investment $D^{i}$ $(i=M, N)$ is endogenous, the effect of the membership in the alliance has 
an ambiguous effect on the equilibrium national security.

\subsection{Private utility and national output}

The civilian private investment effort in each country, to be denoted by $e$, enhances private productivity, $w(e), w^{\prime}(e)>0$. The size of the population is normalized to 1 . For a country outside the alliance, the production function in the civilian sector is

$$
y=w(e)
$$

With a linear investment effect, we have constant returns,

$$
w(e)=e .
$$

Becoming a member in a military alliance is assumed to give rise to a retaliation action by a potential enemy, resulting in an output loss, say $0<$ $\phi<1$. Then the total output is transformed into

$$
y=\phi w(e)
$$

In the absence of saving, consumption equals output, $C=y$.

We assume that the military budget has to be financed by a distortionary income tax with the tax rate denoted by $\tau$. Thus, an efficient level of national security is ruled out and the equilibrium will be of the second best type. The after-tax private utility from consumption is

$$
u(C)=(1-\tau) \phi w(e)-c(e)
$$

where the investment effort is taken to be the subject of a strictly convex effort cost,

$$
c(e)=\frac{1}{2} e^{2} .
$$

Then, the privately optimal investment is found from 


$$
\frac{\partial u}{\partial e}=(1-\tau) \phi w^{\prime}(e)-c^{\prime}(e)=0
$$

and it is

$$
e=(1-\tau) \phi
$$

Consequently, the productivity is

$$
w=(1-\tau) \phi
$$

Therefore, the private indirect utility from the consumption of private goods is

$$
u^{*}(\tau, \phi)=\frac{1}{2}(1-\tau)^{2} \phi^{2} .
$$

The comparative statics is summarized as

$$
\begin{aligned}
& \frac{\partial u^{*}(\tau, \phi)}{\partial \tau}=-(1-\tau) \phi^{2}<0 \\
& \frac{\partial u^{*}(\tau, \phi)}{\partial \phi}=(1-\tau)^{2} \phi>0 .
\end{aligned}
$$

Intuitively, the income tax financing the military budget and the retaliation effect reduce the return on and hence the private investment incentive, hence the productivity and the utility. Such adverse effects on welfare have to be balanced by an increase in the national security.

As the demand is perfectly elastic, the costs of adjustment fall on the producers. Without the military budget with $\tau=0$, the producers' surplus is $y=w(e)=1$. With a costly production of national security, it is reduced to $(1-\tau)^{2} \phi^{2}$. Thus, the loss in the producers' surplus is $\Delta y=1-(1-\tau)^{2} \phi^{2}$. Creating the security is not a free good. 


\subsection{The Welfare Function}

The national welfare is not only dictated by the production capacity of the country. It has two dimensions, the utility of citizens both from the consumption $(C)$ and from the national security $(S)$,

$$
W=u(C) S
$$

As it is convenient to work with logarithms, we denote

$$
w=\log W(\tau, D)=\log \left[\frac{1}{2}(1-\tau)^{2} \phi^{2}\right]+\log \left[s^{i}+\beta D+\mu n F^{\alpha} \exp \left(-s^{i}\right)\right]
$$

As the investment in the national security is a necessity for private consumption, the question is: how much to pay for it? The military budget, financed by a tax on the return on private investment, is

$$
B=\tau y=\tau w(e) \phi=\tau(1-\tau) \phi^{2}
$$

Then, the investment in the domestic defense $D$ is

$$
D=\tau(1-\tau) \phi^{2}-F .
$$

We denote by $\eta \geq 0$ the shadow price of the constraint $D \geq 0$ and carry out the maximization subject of the policy constraint, i.e.

$$
D \geq 0, \eta \geq 0, \eta D=0 .
$$

We focus on the case where no country has the possibility of completely abstaining from the military investment, thus $\tau>0 .{ }^{11}$

Before characterizing the optimal policy, we prove an important lemma.

\footnotetext{
${ }^{11}$ For example, even Monaco has an army with approximately 230 soldiers.
} 
Lemma 1. A sufficient condition for the membership in the alliance to reduce the welfare is $\mu n F^{\alpha} \exp \left(-s^{i}\right)<F$. The negative welfare effect of the membership is reinforced by $\phi<1$ and $\beta<1$.

Proof. As the investment in the domestic capacity is $D=\tau(1-\tau) \phi^{2}-F \geq 0$ and if $\mu n F^{\alpha} \exp (-s)<F$, the welfare comparison can be stated as

$$
\begin{aligned}
w_{M}^{i}(\tau) & =\log \left[\frac{1}{2}(1-\tau)^{2} \phi^{2}\right]+\log \left[s^{i}+\beta\left(\tau(1-\tau) \phi^{2}-F\right)+\mu n F^{\alpha} \exp \left(-s^{i}\right)\right] \\
& \leq \log \left[\frac{1}{2}(1-\tau)^{2} \phi^{2}\right]+\log \left[s^{i}+\tau(1-\tau) \phi^{2}-F+\mu n F^{\alpha} \exp \left(-s^{i}\right)\right] \\
& \leq \log \left[\frac{1}{2}(1-\tau)^{2}\right]+\log \left[s^{i}+\tau(1-\tau)\right]=w_{N}^{i}(\tau) .
\end{aligned}
$$

Therefore, it also holds that $w_{M}^{i}\left(\tau_{M}^{*}\right) \leq w_{N}^{i}\left(\tau_{N}^{*}\right)$ where $\tau_{M}^{*}$ and $\tau_{N}^{*}$ are the optimal tax rates under membership and non-membership, respectively.

Corollary 1. Countries with a high safety classification $s^{i}>\ln (\mu n) F^{\alpha-1}$ abstain from the membership.

We also state,

Corollary 2. It follows that $\mu n F^{\alpha} \exp \left(-s^{i}\right) \geq F$ is a necessary condition for the membership of a country with safety classification $s^{i}$ to increase the welfare.

A natural interpretation is available for the condition in Lemma 1 for non-membership, re-written as

$$
\frac{\mu n F^{\alpha} \exp \left(-s^{i}\right)}{F}<1 .
$$

In a narrow sense, it is the benefit/cost ratio of abstaining from the membership. From a broader perspective, the costs of the membership need to be adjusted also for $\beta$ and to $\phi$. 
Lemma 1 is in line with the common logic that a country with a high safety classification (high $s^{i}$ ) may not seek fo the membership in an alliance while a country with a low safety classification has a stronger incentive to join. The low credibility of the expected commitment of the alliance to the collective safety (low $\mu$ ) reduces the incentive of a potential member to pay for the membership instead of building up her own national defense.

\subsection{Optimal defense budget and the optimal tax rate}

The Lagrangean of an alliance member country is

$$
\begin{aligned}
\mathcal{L}(\tau, D, \lambda, \eta)= & \log \left[\frac{1}{2}(1-\tau)^{2} \phi^{2}\right]+\log \left[s^{i}+\beta D+\mu n F^{\alpha} \exp \left(-s^{i}\right)\right] \\
& +\lambda\left[\tau(1-\tau) \phi^{2}-(D+F)\right]+\eta D .
\end{aligned}
$$

The first-order conditions for the optimum are:

$$
\begin{aligned}
& \frac{\partial \mathcal{L}}{\partial \tau}=\frac{\partial w(\tau, D, \lambda, \eta)}{\partial \tau}+\lambda(1-2 \tau) \phi^{2}=0, \\
& \frac{\partial \mathcal{L}}{\partial D}=\frac{\partial w(\tau, D, \lambda, \eta)}{\partial D}-\lambda+\eta=0, \\
& \frac{\partial \mathcal{L}}{\partial \lambda}=\tau(1-\tau) \phi^{2}-(D+F)=0, \\
& \eta \frac{\partial \mathcal{L}}{\partial \eta}=\eta D=0, \quad D \geq 0, \quad \eta \geq 0 .
\end{aligned}
$$

In the optimal solution, there is a trade-off between the income effect and the security effect arising from the tax. The optimal solution has to balance the welfare loss arising from the tax distortion including the retaliation effect against the improved national security. The income effect of taxation is

$$
\frac{\partial \mathcal{L}(\tau, D, \lambda, \eta)}{\partial \tau}=-\frac{2}{1-\tau}+\lambda(1-2 \tau) \phi^{2}
$$


while the security effect is

$$
\frac{\partial \mathcal{L}(\tau, D, \lambda, \eta)}{\partial D}=\frac{1}{s^{i}+\beta D+\mu n F^{\alpha} \exp \left(-s^{i}\right)}-\lambda+\eta
$$

The marginal valuation of tax revenue thus is

$$
\lambda=\frac{1}{s^{i}+\beta D+\mu n F^{\alpha} \exp \left(-s^{i}\right)}+\eta
$$

With $D$ unconstrained, $\eta=0$, the optimal tax rate is determined from

$$
\frac{\partial w}{\partial \tau}=-\frac{2}{1-\tau}+\frac{(1-2 \tau) \phi^{2}}{s^{i}+\beta\left[\tau(1-\tau) \phi^{2}-F\right]+\mu n F^{\alpha} \exp \left(-s^{i}\right)}=0
$$

which, with a non-negative denominator, simplifies to a linear-quadratic equation in the tax rate,

$$
4 \tau^{2} \beta \phi^{2}-5 \tau \beta \phi^{2}+\beta \phi^{2}-2\left(s^{i}+\mu n F^{\alpha} \exp \left(-s^{i}\right)-\beta F\right)=0 .
$$

As this second order equation has a positive sign for the second term only the smaller root can qualify as a candidate for the maximum. ${ }^{12}$ The solution for the optimal tax of a member country with $D$ unconstrained is

$$
\tau_{M D}^{*}=\frac{1}{8}\left(5-\sqrt{9+32 \frac{s^{i}+\mu n F^{\alpha} \exp \left(-s^{i}\right)-\beta F}{\beta \phi^{2}}}\right) .
$$

Recall that in the current section the analysis is carried out for an alliance member which takes $F$ as exogenous. This solution then states the dispersion of the optimal tax rates for the members in various safety classes, $s^{i} \epsilon\left[s^{L}, s^{U}\right]$.

The solution for a constrained country (including the case with the just

\footnotetext{
${ }^{12}$ It is straightforward to establish the strict concavity of the welfare function. Similarly, the strict convexity of the budget constraint can be established though this requires some algebra. Then the conditions for the Kuhn-Tucker sufficiency theorem hold and the proposed solution qualifies as the global maximum.
} 
binding) is obtained from the budget curve $D=\tau(1-\tau) \phi^{2}-F=0$ and is given by

$$
\tau_{M 0}^{*}=\frac{1}{2}\left(1-\sqrt{1-4 F / \phi^{2}}\right) .
$$

This case can be called complete crowding-out of the domestic defense capacity of an alliance member. It points to the case of a country in a high safety class. To have a real root, we parametrize the model with an assumption

Assumption 1. $F<\phi^{2} / 4$.

Lemma 2. For a member with a positive national army, an increase in the cost of membership in the alliance results in re-optimization of the optimal tax rate making it lower for a member country with low $s^{i}$ but higher for countries with "sufficiently" high $s^{i}$. In particular, a member which has given up her national defense, an increase in the cost of membership results in a higher tax rate.

Proof. In the solution for the optimal tax rate, $\mu n F^{\alpha} \exp \left(-s^{i}\right)-\beta F>$ $\mu n F^{\alpha} \exp \left(-s^{i}\right)-F>0$ for any member by Lemma 1. Its derivative with respect to $F, \alpha \mu n F^{\alpha-1} \exp \left(-s^{i}\right)-\beta$, is positive when $s^{i}$ is low enough (i.e. if $\left.s^{i}<\ln (\alpha / \beta)+\ln \left(\mu n F^{\alpha-1}\right)\right)$ making $\partial \tau_{M D}^{*} / \partial F<0$ but negative when $s^{i}$ is high enough, (i.e. if $\left.\left.s^{i}>\ln (\alpha / \beta)+\ln (\mu n) F^{\alpha-1}\right)\right)$ making $\partial \tau_{M D}^{*} / \partial F>0$. The latter part of the Lemma follows from the tax rate (13).

Lemma 2 reveals an unexpected conclusion: for member countries in a low safety class, an increase in the cost of membership in an alliance results in lower tax rate. There is an intuitive explanation available: the safety effect dominates the income effect, making it worthwhile to economize the domestic defense.

It is helpful to consider the solution graphically. Let us draw the isowelfare curves in Figure 1 in terms of the tax rate (on the horizontal axis) and the domestic defense expenditure (on the vertical axis). Totally differ- 


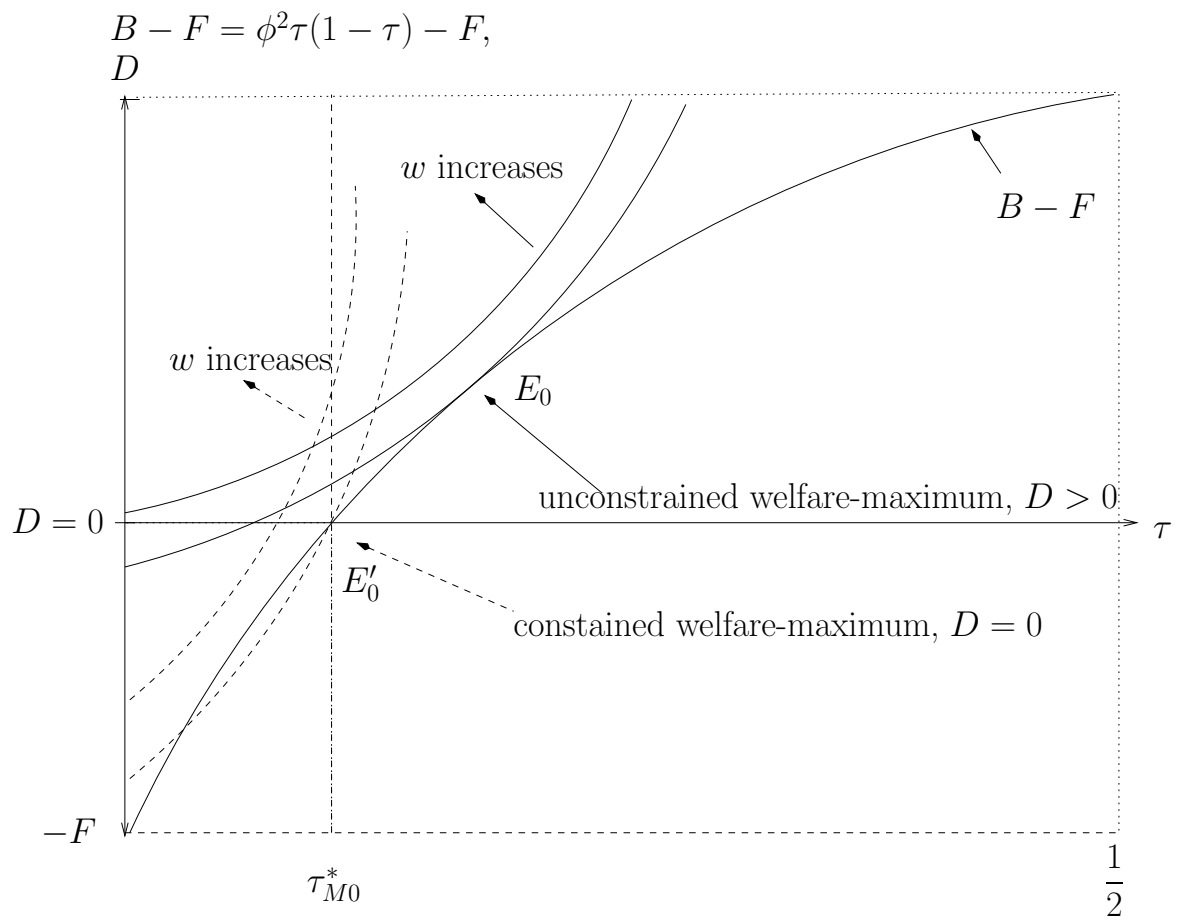

Figure 1: Indifference curves for constrained $(D=0)$ and unconstrained $(D>0)$ welfare maxima respectively.

entiating (8) yields the iso-welfare condition

$$
d \bar{w}=-\frac{2}{1-\tau} d \tau+\frac{\beta}{s^{i}+\beta D+\mu n F^{\alpha} \exp \left\{-s^{i}\right\}} d D=0 .
$$

Hence, the slopes of the iso-welfare curves are

$$
\frac{d D}{d \tau}=\frac{2\left(s^{i}+\beta D+\mu n F^{\alpha} \exp \left\{-s^{i}\right\}\right)}{\beta(1-\tau)}>0 .
$$

As $d^{2} D /(d \tau)^{2}=(d D / d \tau) /(1-\tau)>0$, the indifference curves are upwardsloping convex curves in the $(\tau, D)$ axes and a higher iso-welfare curve represents a higher welfare. 
The budget curve of the government,

$$
D=\tau(1-\tau) \phi^{2}-F
$$

is a second-order parable in the $(\tau, D)$ axes, peaking at $\tau=0.5$. Setting $\tau=0$, we have $D=-F$. Moreover, its slope is $\partial D / \partial \tau=1-2 \tau>0$ when $\tau<0.5$. An iso-welfare curve is hence tangent to the budget curve at a point, say $E_{0}$ to the left of the peak, $\tau<0.5$. The tangency point $E_{0}$ represents the optimal solution for an unconstrained member country. The point $E_{0}^{\prime}$, instead represents the optimal solution for a member country with $D=0$. Intuitively, a country with a low safety classification chooses $D>0$. In terms of Figure 1, the slope of her iso-welfare curve at $E_{0}^{\prime}($ with $D=0$ ) is less than the slope of her budget curve

$$
\frac{2\left(s^{i}+\mu n F^{\alpha} \exp \left(-s^{i}\right)\right)}{1-\tau}<1-2 \tau .
$$

To compare the development of the slopes of the iso-welfare loci when one moves to a higher safety class, evaluate the effect on the slope,

$$
\partial\left(s^{i}+\mu n F^{\alpha} \exp \left(-s^{i}\right)\right) / \partial s^{i}
$$

to find out that it is positive when $\mu n F^{\alpha} \exp \left(-s^{i}\right)<1$. The slopes are equal if $2\left(s^{i}+\mu n F^{\alpha} \exp \left(-s^{i}\right)\right)=(1-\tau)(1-2 \tau)$. This condition implicitly determines the critical value of $s^{i}$ at which one observes the complete crowding-out. Is is unique as its left-hand side is monotone in $s^{i}$, i.e. its derivative $2\left(1-\mu n F^{\alpha} \exp \left(-s^{i}\right)\right)$ is everywhere positive (by Assumption 2 to be stated below). Recalling Lemma 1, we obtained above that for a membership, it is necessary that $\mu n F^{\alpha} \exp \left(-s^{i}\right)>F$. To combine the two conditions, the subsequent analysis is carried out under an assumption,

\section{Assumption 2.}

$$
F<\mu n F^{\alpha} \exp (-s)<1
$$


Together with Assumption 1, this assumption states the feasibility region in terms of the admissible parameter values.

Above we have derived a non-participation condition $\mu n F^{\alpha} \exp \left(-s^{i}\right)<F$ faced by potential members stating that the benefit/cost ratio is not sufficient to justify the membership. This condition can be stated in terms of the safety class of the non-member country as $s^{i}>\ln \left(\mu n F^{\alpha-1}\right)$. For those countries, the remaining problem is to optimize their national defense budget and choose the associated tax rate, say $\tau_{N}^{*}$, optimally. This can be undertaken by imposing $\mu=F=0, \beta=\phi=1$ in the tax solution of a member country and the solution is

$$
\tau_{N}^{*}=\frac{1}{8}\left(5-\sqrt{9+32 s^{i}}\right)
$$

The condition for a positive tax rate of a non-member country then is found from

$$
\left.\frac{\partial w}{\partial \tau}\right|_{\tau=0}=-2+\frac{1}{s^{i}}>0
$$

stating the upper limit for the safety class. Such a country definitively has a positive national defense, $D=\tau(1-\tau)>0$. The safety class of a non-member with positive national defense thus satiesfies

$$
\ln \left(\mu n F^{\alpha-1}\right)<s^{i}<\frac{1}{2} .
$$

For a non-member country with $s^{i}<1 / 2$ there is thus no need to check the value of the shadow price, $\eta$. It is definitively zero.

We now state some key comparative static effects concerning the optimal tax rate of a country in a low safe class:

Lemma 3. Among those members which plan to maintain a national defense capacity, $D>0$ over and above the contribution to the collective security, it holds :

1. The optimal tax rate $\tau_{M D}^{*}$ is declining in the safety classification of the country, $\partial \tau_{M D}^{*} / \partial s^{i}<0$. 
2. A greater retaliation effect (smaller $\phi$ ) reduces the tax rate $-\partial \tau_{M D}^{*} / \partial \phi<$ 0 , (as the marginal utility of consumption becomes greater relative to the marginal effect on security).

3. Increased moral hazard in terms of national security effort (lower $\beta$ ) reduces the tax rate, $-\tau_{M D}^{*} / \partial \beta<0$,

Proof. Straightforward derivation.

Lemma 3 has established a mechanism pointing to moral hazard associated with the membership. We suggest, however, that the most dramatic moral hazard results from the incremental security,

Proposition 1. (Free-riding incentive) Among those member countries which plan to maintain a national defense capacity $D$ over and above the contribution to the collective security, the optimal tax rate is unambiguously smaller the greater the incremental collective security is,

$$
\frac{\partial \tau_{M D}^{*}}{\partial(\mu n)}<0
$$

Proof. Straightforward derivation.

We also state a corollary

Corollary 3. (i) Imperfect credibility of the commitment of the alliance results in greater domestic defense capacity,

$$
-\frac{\partial D}{\partial \mu}>0 .
$$

(ii) The member country with $D>0$ always invests less in her defense budget than a non-member, $B_{M D}^{*}<B_{N}^{*}$,

(iii) The domestic defense capacity of a member country is always smaller than that of a non-member country, $0 \leq D_{M D}^{*}<D_{N}^{*}$. 
Proof. The optimal tax result $\tau_{M D}^{*}<\tau_{N}^{*} \leq 1 / 2$ implies that (as $\tau<1 / 2$ ), $B_{M D}^{*}=\tau_{M D}^{*}\left(1-\tau_{M D}^{*}\right) \phi^{2}<B_{N}^{*}=\tau_{N}^{*}\left(1-\tau_{N}^{*}\right)$ as $\partial(\tau(1-\tau)) / \partial \tau>0$. Therefore, $D_{M}^{*}=\tau_{M}^{*}\left(1-\tau_{M}^{*}\right) \phi^{2}-F<D_{N}^{*}=\tau_{N}^{*}\left(1-\tau_{N}^{*}\right)$.

\section{The option value of the alliance member- ship}

Above we have analyzed the defense policy of countries which are members and which are non-members. In this section, we raise the question under what conditions it is optimal for a country to seek for a membership. ${ }^{13}$

Above, the optimal policy variables were denoted by $\tau_{M}^{*}, D_{M}^{*}$ and the maximized welfare by $w_{M}^{*}=\log W_{M}^{*}$ under the optimal policy of membership. They were denoted by $\tau_{N}^{*}, D_{N}^{*}$ and the maximized welfare by $w_{N}^{*}=\log W_{N}^{*}$ when it was not welfare-increasing to seeks for a membership. The value of the option to join then can be stated as

$$
v=\max \left[0, w_{M}^{*}-w_{N}^{*}\right] .
$$

The stars indicate that the military budget is adjusted optimally. Then, we prove,

Proposition 2. When positive, the value of the membership option satisfies

1. $w_{M}-w_{N}$ is decreasing in the basic safety of the country, $s^{i}$.

2. $w_{M}-w_{N}$ is increasing in the incremental security provided by the alliance, $\mu n$, in the retaliation effect, $\phi$, and in the commitment to the domestic defense effort, $\beta$.

3. The effect of the membership fee $F$ on the option value is ambiguous.

\footnotetext{
${ }^{13}$ We pass the issue of a potential entry barrier not that it is irrelevant but because it is a different issue.
} 
Proof. It is sufficient to resort to the graphical analysis and refer to Figure 1 and the welfare iso-welfare curves (7) and the budget curve (9). The basic safety $s^{i}$ affects the welfare of a member $w_{M}^{*}$ through two counteracting security effects. The positive direct effect is partially counteracted through the dilution of the alliance public good effect, see (7). The welfare of a nonmember, $w_{N}^{*}$ in (23) is increased. Therefore, the difference in $w_{M}^{*}-w_{N}^{*}$ is reduced resulting in $\partial v / \partial s^{i}<0$. In terms if Figure 1 , as the optimal tax rate is decreased (see equation (12)) and so is the military budget, the iso-welfare curve in Figure 1 becomes steeper. The incremental security effect, $\mu n$ and the $\beta$-parameter enter only the welfare of a member, see (7) increasing it and resulting similarly in a lower optimal tax. Thus, $\partial v / \partial((\mu n)>0,-\partial v / \partial \beta<$ 0 . The retaliation effect $\phi$ creates both an income effect in (7) and tilts the budget curve in Figure 1 downward resulting in $-\partial v / \partial \phi<0$. The cost of membership, $F$, has both a positive security effect and a negative budget effect of a member but no effect on a non-member. The iso-welfare curves become steeper while the budget curve moves downward precisely by the amount of an increase in $F$. This results in a lower or higher optimal tax rate (stated above in Lemma 2) and (typically) a reduction in the domestic military investment, $D$. The total effect on the optimized welfare

$$
d w=\left(\frac{\partial w}{\partial \tau}\right)\left(\frac{\partial \tau}{\partial F}\right) d F+\left(\frac{\partial w}{\partial D}\right)\left(\frac{\partial D}{\partial F}\right) d F .
$$

remains, however, ambiguous.

\section{The alliance equilibrium}

\subsection{Membership without commitment: a median voter approach}

By raising the question of the value of the alliance option for a potential member, the starting point of our paper has been the heterogeneity of the 
potential (and existing) members. For some of them, the option value may be positive, for others, it may be zero. In the earlier sections, our focus was in the analysis of a single member with a particular safety classification. The mechanisms which are decisive in the determination of the value of the membership option were identified. We now turn to endogenize the size of the alliance and the magnitude of the entry fee, $F$, in the spirit of the median voter theorem. ${ }^{14}$

In the case without commitment, each member is assumed to vote for the resource requirement $F$ on purely national grounds. We observed above in Proposition 2 that a rise in the membership fee may raise the welfare of some members, $\partial\left(w_{M}-w_{N}\right) / \partial F>0$ but reduce it for others $\partial\left(w_{M}-w_{N}\right) / \partial F<$ 0 depending on the safety classification. There is a particular member for which the condition $\partial\left(w_{M}-w_{N}\right) / \partial F=0$ then obviously holds. It is appropriate to identify this member as the median voter. After voting, the suggestion by the median voter is declared and some of the members with a high safety classification terminate the membership. Under membership without commitment, the size of the alliance shrinks. We recall now that the safety classification among the members is assumed to be uniformly distributed on

$$
\left[s^{L}, s^{U}\right]
$$

The members express their preference for $F$ and the proposition of the median voter is the winning one. ${ }^{15}$ Consequently, some members leave and others may enter.

\footnotetext{
${ }^{14}$ To make sure, there is no voting in NATO as the decision-making is based on consensus. However, the decision-making has several steps. A series of active consultations take place until a decision that is acceptable to all members is reached. Our abstract analysis in this section is the analytic counterpart of such a series of consultations and we choose to call it "median voter approach" as the consensus decision has to be established through some logical procedure.

${ }^{15}$ Below we find out that for any given safety class $s^{i}$, the proposal concerning $F$ is unique. Therefore, the preferences of the members are single-peaked and the voting will select the outcome most preferred by the median voter.
} 
The safety classification of the (original) median voter is

$$
s^{M}=\frac{s^{L}+s^{U}}{2} .
$$

The median voter is taken to be forward-looking in her proposition concerning $F$ and paying attention to her subsequent national security solution, i.e. her optimal tax rate, $\tau$, and the national defense, $D$. As some members will choose to terminate the membership after learning the proposition of the median voter, one might ask why not incorporate those consequences into the decision of the median voter in the first place. The answer is that she can not. She will not be the median voter in the successive voting rounds after the exit of some of the members and adjustment of the size of the alliance.

In a coalition of $n$ members, the welfare maximizing $F$ of the median voter of the first voting round is

$$
\begin{aligned}
F^{M} & =\arg \max _{F} w_{M} \\
& =\arg \max _{F}\left\{\log \left[\frac{1}{2}(1-\tau(F))^{2} \phi^{2}\right]\right. \\
& +\log \left[s^{M}+\beta \tau(F)(1-\tau(F)) \phi^{2}+\left(\mu n F^{\alpha} \exp \left(-s^{M}\right)-\beta F\right)\right] \\
& \left.+\eta_{M}\left[\phi^{2} \tau(F)(1-\tau(F))-F\right]\right\}
\end{aligned}
$$

where $\eta_{M} \geq 0$ is the associated shadow price and $\tau(F)$ is the optimal tax rate given $F$. The first-order condition for its maximum is given by

$$
\begin{gathered}
0=\frac{\partial w_{M}^{*}}{\partial F}=\left[-\frac{2}{1-\tau}+\beta \phi^{2} \frac{1-2 \tau}{S}\right] \tau_{F}+\left(\frac{1}{S}\right)\left[\alpha \mu n F^{\alpha-1} \exp \left\{-s^{M}\right\}-\beta\right] \\
+\eta_{M}\left[\phi^{2} \tau_{F}(1-2 \tau)-1\right] .
\end{gathered}
$$

where we have incorporated the dependence of the optimal tax rate on $F$ 
and where we have denoted

$$
S=s^{M}+\beta \tau(F)(1-\tau(F)) \phi^{2}+\left(\mu n F^{\alpha} \exp \left(-s^{M}\right)-\beta F\right)>0 .
$$

The first-order condition with respect to the tax rate from Section 2 is

$$
\frac{\partial w}{\partial \tau}=-\frac{2}{1-\tau}+\phi^{2} \frac{1-2 \tau}{S}=0
$$

We notice, however, that the solution becomes quite involved when $\beta<1$. Therefore, we focus on the case with $\beta=1 .^{16}$ Then, the first-order condition is reduced to

$$
\frac{\partial w_{M}^{*}}{\partial F}=\left(\frac{1}{S}\right)\left[\alpha \mu n F^{\alpha-1} \exp \left(-s^{M}\right)-1\right]+\eta_{M}\left[\phi^{2} \tau_{F}(1-2 \tau)-1\right]=0 .
$$

If the median voter plans to have a positive national defense $D>0, \eta_{M}=$ 0 and the cost of membership suggested by her is

$$
F^{M}=\sqrt[1-\alpha]{\left(n / \exp \left(s^{M}\right)\right)(\alpha \mu)}
$$

which, by the second order condition,

$$
\alpha(\alpha-1) \alpha \mu n F^{\alpha-2} \exp \left(-s^{M}\right)<0
$$

is the maximum. Therefore,

Proposition 3. The median voter suggests the participation fee,

$$
F^{M}=\sqrt[1-\alpha]{\left(\frac{n}{\exp \left(s^{M}\right)}\right)(\alpha \mu)}
$$

\footnotetext{
${ }^{16}$ If $\beta<1$, there will be an additional parameter in the denominator of the solution for $F^{M}$ below. If $\tau_{F}<0$, its effect is to raise the proposal of the median voter. If $\tau_{F}>0$, its effect cannot be determined.
} 
for the alliance members when it is optimal for her to have a positive national defense, $D>0$.

Corollary 4. The proposal of the median voter concerning the participation fee, $F$, is increasing in the incremental security created by the alliance, $\mu n$, but decreasing in the security classification of the median voter, $s^{M}$.

After the proposal, some members leave the alliance or new may enter. With free entry and exit to the alliance, and as $\alpha, \mu$ and $\beta$ are parameters, the dynamics of the alliance is dictated by the adjustment of its membership, $n$, and therefore by the safety classification of the new median voters, $s^{M}$. It is the ratio

$$
n / \exp \left\{s^{M}\right\}
$$

which becomes decisive. After the proposal is made public a new median voter is identified. If the number of the members increases so does the safety classification of the (new) median voter and vice versa. This follows from that the new members are always on the safe side of the median voter. The ratio $n / \exp \left(s^{M}\right)$, however, may be increasing, constant or decreasing in $n$ during consecutive voting rounds. We first prove:

Lemma 4. Given the proposal of the median voter, $F^{M}$, it is sufficient for a country with a high safety classification to abstain from the membership that the retaliation affect is strong enough (small $\phi$ ) and/or that the dilution of the commitment of the country to defend itself nationally is strong enough ( $\beta$ small).

Proof. The option value of the membership for the countries with a high safety classification $s^{H}>s^{M}$ is dictated by the condition

$$
v=\max \left[0, w_{M}^{*}\left(s^{H}\right)-w_{N}^{*}\left(s^{H}\right)\right], \quad s^{H}>s^{M} .
$$


Evaluating at $s=s^{H}>s^{M}, F=F^{M}$, it holds for a member

$$
\begin{aligned}
w_{M}^{*}\left(s^{H}\right) & =\log \left[\frac{1}{2}\left(1-\tau\left(F^{M}\right)\right)^{2} \phi^{2}\right]+\log \left[s^{H}+\beta \tau\left(F^{M}\right)\left(1-\tau\left(F^{M}\right)\right) \phi^{2}\right. \\
& \left.+\left(\mu n F^{M, \alpha-1} \exp \left\{-s^{H}\right\}-\beta\right) F^{M}\right]
\end{aligned}
$$

and for a non-member,

$$
w_{N}^{*}\left(s^{H}\right)=\log \left[\frac{1}{2}\left(1-\tau^{*}\right)^{2}\right]+\log \left[s^{H}+\tau^{*}\left(1-\tau^{*}\right) .\right]
$$

To carry out the comparison, we first recall

$$
\phi<1, \beta<1, \tau\left(F^{M}\right)>\tau^{*}, \quad 1-\tau\left(F^{M}\right)<1-\tau^{*}
$$

Thus, there are counteracting mechanisms in the welfare comparison related to these effects. However, we are able to trace those mechanisms which are sufficient for making a country with a high safety classification abstain from the membership given the membership fee $F^{M}$ proposed by the median voter. Indeed for a country with a high safety classification, the last term in $w_{M}^{*}\left(s^{H}\right)$, i.e. $\left(\mu n F^{M, \alpha-1} \exp \left\{-s^{H}\right\}-\beta\right) F^{M}$ is small and with sufficiently high $s^{H}$ and it is negative, cf. Lemma 1. Collecting the effects, it holds for a country with a high safety classification, $w_{M}^{*}\left(s^{H}\right)<w_{N}^{*}\left(s^{H}\right)$.

Stated verbally, and given the membership fee proposed by the median voter, say $F^{*}$, the option value of the membership for the potential members with a high safety classification is zero while it is positive for the potential members with a low safety classification. It is now possible to characterize the limit to the group of the countries with a high safety classification which belong to the alliance. The proposed fee satisfies $\alpha \mu n F^{M^{\alpha-1}} \exp \left(-s^{M}\right)-1=0$. From Lemma 1, the high- $s^{i}$ countries with $\mu n F^{\alpha-1} \exp \left(-s^{H}\right)<1$ abstain from the membership. Therefore, $\mu n F^{M^{\alpha-1}} \exp \left(-s^{H}\right)<\alpha \mu n F^{M^{\alpha-1}} \exp \left(-s^{M}\right)$, or $\exp \left(s^{M}-s^{H}\right)<\alpha$, i.e. $s^{H}>s^{M}-\ln \alpha$. The non-empty group of countries 
with a higher safety classification than the median voter is stretched up to the limit $s^{M}-\ln \alpha$ (which exceeds $s^{M}$ as $\alpha<1$ ).

Above we focused on the case where it is optimal for the median voter to have a positive national defense. It is not excluded that the equilibrium of the median voter is located at the corner with $D=0$. What is then her proposal when compared with the one detected above? This case corresponds to the equilibrium $E_{0}^{\prime}$ in Figure 1. Those countries which have a high safety classification $s^{H}>s^{M}$, but which stay as members have $D=0$, too. It is clear from Figure 1 that in such a case, the median voter would choose a lower tax rate necessitating a lower membership fee $F$.

Corollary 5. If the median voter plans to abstain from a national army, she will propose a lower participation fee than she would propose in the case where she plans to have a national army.

We now prove the key results concerning the voting dynamics.

Proposition 4. (Voting equilibrium) Denote the candidate for the voting equilibrium by a triple $\left(\tilde{s}^{m}, F^{r}, \tilde{n}\right)$ where $\tilde{s}^{m}$ is some safety class among the potential alliance members with $s^{L}<\tilde{s}^{m}<s^{M}$. Then, a decreasing ratio of the size of the alliance relative to the safety classification $n / \exp \left(s^{M}\right)$ in $n$ is sufficient for the existence of a stable alliance equilibrium such that for all remaining members $s^{i} \epsilon\left[s^{L}, \tilde{s}^{m}\right]$ it holds that

$$
\begin{gathered}
w_{i}^{M}(\tilde{F}) \geq w_{i}^{N}(\tilde{F}) \quad s^{i} \in\left[s^{L}, \tilde{s}^{m}\right] \quad \text { (participation constraints) } \\
\tau_{i}=\tau_{i}^{*} \quad s^{i} \epsilon\left[s^{L}, \tilde{s}^{m}\right] \quad \text { (incentive constraints) }
\end{gathered}
$$

and that for all non-mebers it holds that

$$
w_{i}^{M}(\tilde{F})<w_{i}^{N}(\tilde{F}) \quad s^{i} \epsilon\left[\tilde{s}^{m}, \tilde{s}^{U}\right] \quad(\text { non - participation constraints }) .
$$


Proof. The voting dynamics goes as follows. After the first voting round with $n$ potential members and once the proposition $F^{M}$ is on the table, the countries with a high safety classification have an incentive to abstain from the alliance. To see this, recall that the proposed fee satisfies $\alpha \mu n F^{M^{\alpha-1}} \exp \left\{-s^{M}\right\}-$ $1=0$. From Lemma 1 , the high- $s^{i}$ countries with $\mu n F^{\alpha-1} \exp \left\{-s^{i}\right\}<1$ have an incentive not to join the alliance. To be quite precise, it is the group of countries with $\exp \left(s^{i}-s^{M}\right)>1 / \alpha$ i.e. $s^{i}>s^{M}-\ln \alpha$ which leave. Notice that $\ln \alpha<0$ as $\alpha<0$. It is then easy to establish that after the first voting round, and under the uniform distribution, the safety classification of the new median voter is reduced to, say $s^{M^{\prime}}$, with

$$
s^{M^{\prime}}=s^{M}-\frac{s^{M}-s^{L}+\ln \alpha}{2}<s^{M} .
$$

Then, when the ratio $n / \exp \left\{s^{M}\right\}$ is decreasing in $n$, the new median voter $\mathrm{M}^{\prime}$ proposes a higher participation fee, say $F^{M^{\prime}}$ satisfying $F^{M^{\prime}}<F^{M}$ (see the previous Proposition above). Then, some of the high-safety members who did not join will re-optimize finding it welfare-increasing to join. This will then result again in a new median voter suggesting this time a lower membership fee making some of the potential members with high safety classification abstain. The process converges towards a stable equilibrium with a triple to be denoted by $\left(\tilde{s}^{m}, \tilde{F}^{m}, \tilde{n}\right)$ with the properties $\tilde{s}^{m}<s^{M}, \tilde{F}<F^{M}, \tilde{n}<n$. We notice that if the ratio $n / \exp \left(s^{M}\right)$ is constant the equilibrium will be attained at the initial proposal as the next median voter has no incentive to change it.

Proposition 5. An increasing ratio of the size of the alliance relative to the safety classification $n / \exp \left(s^{M}\right)$, is sufficient for the existence of a stable alliance equilibrium is sufficient for an degenerated alliance equilibrium with one member only, the country with the lowest safety classification.

Proof. During the second voting round, the proposed membership fee $F$ declines from what it was during the first round. Those who left the alliance 
during the first voting round do not rejoin. Some of those with a lower security classification, $s^{i}<s^{M^{\prime}}$ leave with the decline in the proposed $F$. The process continues to the limit with $n=1$.

\subsection{Membership with costly termination: multiple equi- libria}

The risk classification of each member is revealed in stage 1 and its distribution becomes public knowledge. Suppose now that the membership in the alliance is considered as commitment and can be terminated only at a cost. ${ }^{17}$ Then, each member finds it necessary to form expectations concerning on how many members are willing to pay the cost of termination of the membership. The expectations concern about the behavior of the other members. The number of remaining members determines the quality and the distribution of the collective public good $G$. By implication, the expectations concern which member is going to be the median voter and what her suggestion will be. Two equilibria are possible, a narrow one and a broad one.

Proposition 6. (Multiple equilibria) Under a costly termination of the membership, expectations of a median voter with a high safety classification result in a large alliance while expectations of a median voter with a low safety classification result in a small alliance.

Proof. Once the median voter has a high safety classification, Proposition 3 above points to the fact that he will suggest a low membership fee, $F$. Then, the alliance members expect that most of the members will not be engaged in a costly termination process and the size of the alliance remains large. It is the opposite which holds once the median voter belongs to a low safety class.

\footnotetext{
${ }^{17}$ Such costs could include, among others, the entry barrier should the exiting nation reconsider the option of the membership later on.
} 


\section{Final remarks}

The paper has introduced a structural approach to the problem of whether a country under a security threat should find it welfare-improving to enter a defense alliance or not. The approach adopted has been welfarist leading to a characterization of the option value of a membership. Several adverse incentive effects have been identified for those countries which exercise the option. The key feature of the analysis has been the heterogeneity of the alliance members in terms of their safety classification. Consequently, the analysis of the alliance equilibrium revealed several mechanisms which were found relevant to explore. The paper is obviously not only an academic exercise. With the recent security threats within the European continent, its approach is of relevance for policy makers in several countries in Europe.

\section{References}

R. Boadway and M. Hayaschi. Country size and the voluntary provision of international public goods. European Journal of Political Economy, 15: 619-638, 1999.

S. M. Chowdhury and R. M. Sheremeta. A generalized tullock contest. Public Choice, 147:413 - 420, 2011.

I. Ehrlich and G.S. Becker. Market insurance, self-insurance, and selfprotectio. Journal of Political Economy, 80:623-648, 1972.

W. A. Gamson. A theory of coalition formation. American Sociological Review, 26:373 - 382, 1961.

J. Hirshleifer. From weakest-link to best shot: The voluntary provision of public goods. Public Choice, 41(3):371 - 386, 1983. 
J. Hirshleifer. Conflict and rent-seeking success functions: Ratio vs. difference models of relative success. Public Choice, 63:101-112, 1989.

T. Ihori, M. McGuire, and S. Nakagawa. International security, multiple public good provisions, and the exploitation hypothesis. Defence and Peace Economics, 25:213-229, 2014.

K. A. Konrad. Strategy and Dynamics in Contests. Oxford University Press, Oxford, 2009.

T. Lohse, J. Robledo, and U. Schmidt. Self-insurance and self-protection as public goods. Journal of Risk and Insurance, 79:57 - 76, 2012.

I. Macho-Stadler and L. Xue. Winners and losers from the gradual formation of trading blocs. Economica, 74:664-681, 2007.

M. Olson. The Logic of Collective Action: public goods and the theory of groups. Harvard University Press, Cambridge Massachusetts, 1965.

M. Olson and R. Zeckhauser. An economic theory of alliances. Review of Economics and Statistics, 48(3):266 - 279, 1966.

D. Ray and R. Vohra. A theory of endogenous coalition structures. Games and Economic Behavior, 26:286 - 336, 1999.

T. Sandler and K. Hartley. Economics of alliances: The lessons for collective action. Journal of Economic Literature, XXXIX:869 - 896, 2001.

T. C. Schelling. The strategy of conflict. Harvard University, 1960.

G. Tullock. The welfare cosst of tariffs, monopolies, and thefts. Western Economic Journal, 5:224 - 232, 1967.

G. Tullock. Toward a Theory of the Rent-Seeking Society, chapter Efficient Rent-Seeking, pages 97 - 112. Texas A\&M University Pres, 1980. 
J. van Ypersele de Strihou. Sharing the defense burden among western allies. Review of Economics and Statistics, 49(4):527 - 536, 1967.

S. Weber and H. Wiesmeth. Economic models of NATO. Journal of Public Economics, 46:181 - 197, 1991. 